\title{
Helicobacter Pylori Eradication May Increase Body Mass Index, But the Effect May Not Last Long. A 10-year Observational Study in Male Patients
}

\author{
Takayuki Imada ${ }^{1}$, Motowo Mizuno ${ }^{2}$, Susumu Take ${ }^{3}$, Kuniharu Ishiki ${ }^{1}$, Tetsuji Okuno ${ }^{1}$, \\ Tomowo Yoshida ${ }^{1}$, Hiroyuki Okada ${ }^{4}$, and Kazuhide Yamamoto ${ }^{5}$
}

'Department of Internal Medicine, Nippon Kokan Fukuyama Hospital, Daimon-cho, Fukuyama, Japan

'Department of Gastroenterology and Hepatology,Kurashiki Central Hospital, Kurashiki, Japan ${ }^{3}$ Department of Internal Medicine, Fukuwatari Municipal Hospital, Okayama, Japan ${ }^{4}$ Department of Gastroenterology and Hepatology, Okayama University Graduate School of Medicine, Dentistry and Pharmaceutical Sciences, Okayama, Japan

${ }^{5}$ Okayama Saiseikai Hospital, Okayama, Japan

\author{
Corresponding author: \\ Dr. Takayuki Imada \\ Department of Internal Medicine, \\ Nippon Kokan Fukuyama Hospital, \\ Daimon-cho, Fukuyama, Hiroshima, \\ 721-0927, Japan \\ E-mail: takayuki_imada@nkfh.or.jp
}

\section{ABSTRACT}

Background/Aims: We retrospectively investigated the long-term change in body mass index (BMI) in our Japanese cohort of patients to elucidate whether Helicobacter pylori eradication results in weight gain.

Methodology: Four hundred and thirty-five patients who had received eradication therapy and 167 who were $\mathrm{H}$. pylori-positive but declined treatment were followed for 10 years or longer, and their BMls were recorded.

Results: After 10 years, BMI significantly increased from baseline values in both the eradication and the no-eradication groups. However, the increase was significantly more in the eradication group than in the no-eradication group. The greater weight gain in the eradication group could largely be accounted for by gain above a lower baseline value, and occurred only within the first year after eradication. The lower baseline BMI of the eradication group correlated with their higher prevalence of peptic ulcers. From the one-year time point onward, gradual weight gain occurred at a similar rate in both groups. At the 10-year point, the BMIs of the two groups were not significantly different.

Conclusions: Eradication of $\mathrm{H}$. pylori resulted in a short-term weight gain that likely was related to the eradication and their ulcer healing, but the effect did not last thereafter.

Key words: Helicobacter pylori, eradication therapy, body mass index, obesity

\section{INTRODUCTION}

More than ten years have passed since Helicobacter pylori eradication 
H. pylori cures certain peptic ulcers (1-3) and reduces the risk of gastric cancer (4-7). However, several concerns regarding possible adverse effects of eradicating $\mathrm{H}$. pylori have been raised. The development or worsening of reflux esophagitis is one of the concerns (8), but we have found this risk to be minimal or nonexistent $(9,10)$. The possibility of promoting or exacerbating obesity also has raised concern (11-16), but data regarding this issue, especially of long-term observation, are inconclusive.

We have been examining the effects of $\mathrm{H}$. pylori eradication therapy on several medical issues in a large cohort of Japanese patients $(4,9,10,17-24)$, including the prevention of gastric cancer $(4,22,23)$, factors associated with failure of eradication therapy $(17,20,21)$, and the re-infection rate after cure of $\mathrm{H}$. pylori infection $(18,24)$.In the present study, we retrospectively investigated the change of body mass index (BMI) in this cohort of patients who had been followed up for 10 years or longer to determine whether $\mathrm{H}$. pylori eradication resulted in weight gain or obesity.

\section{PATIENTS AND METHODS}

We studied 602 male patients aged 60 years or younger who had visited the outpatient clinic of Nippon Kokan Fukuyama Hospital for esophagogastroduodenoscopy and $\mathrm{H}$. pylori examination, and had been followed up for 10 years or more. Indications for esophagogastroduodenoscopy were health-check in 494 patients, dyspeptic symptoms in 86 , and upper gastrointestinal bleeding in 22. At the endoscopy, we evaluated for peptic ulcers, gastric mucosal histology and $\mathrm{H}$. pylori infection, and confirmed that there was no gastric cancer or other malignancies. One hundred forty-one patients had gastric ulcer, 223 had duodenal ulcer, 152 had both diseases, and 86 had no ulcer. The subjects consisted of two groups: 1) 435 patients who had received eradication therapy from May 1995 and December 2001 and achieved cure of $\mathrm{H}$. pylori infection (eradication group), and 2) 167 who had tested positive for $\mathrm{H}$. pylori infection but declined eradication therapy (no-eradication, control group). Both groups were followed for 10 years or more after the completion of eradication therapy or the initial examination. Endoscopic examination was performed annually in each subject, and BMI was recorded at the time of endoscopy. Females were not included in this study because pregnancy or menopause may have affected their weight. Also, most patients were male factory workers at the JFE Steel Corporation. Patients with a history of surgery on the gastrointestinal tract, cancer, or taking corticosteroids were excluded from the study.

$\mathrm{H}$. pylori infection was diagnosed by at least one test: gastric histology, tissue culture of gastric biopsies, ${ }^{13} \mathrm{C}$-urea breath test (UBIT, Otsuka Pharmaceutical Co., LTD, Tokyo, Japan), ora rapid urease test (MR UREA S; Institute of Immunology Co., LTD, Tokyo, Japan). Patients in the eradication group received $\mathrm{H}$. pylori eradication therapy as described (4). One hundred and seventy-one patients from June 1995 to August 1999 received two weeks of dual therapy consisting of amoxicillin $750 \mathrm{mg}$ b.i.d. and proton pump inhibitor (omeprazole $20 \mathrm{mg}$ b.i.d. or lansoprazole $30 \mathrm{mg}$ b.i.d.), and 264 patients from February 1997 to December 2001received one week of triple therapy consisting of amoxicillin $750 \mathrm{mg}$ b.i.d., clarithromycin $200 \mathrm{mg}$ or 400 mg b.i.d., and proton pump inhibitor (omeprazole 20 $\mathrm{mg}$ b.i.d., lansoprazole $30 \mathrm{mg}$ b.i.d. or rabeprazole 10 $\mathrm{mg}$ b.i.d.), ortriple therapy consisting of amoxicillin 750 mg b.i.d.,metronidazole $500 \mathrm{mg}$ b.i.d., and proton pump inhibitor. Before the Japanese government approved the national health insurance coverage of the eradication therapy of H. pylori in November 2000, we mostly used the dual therapy on the basis of reports on this therapy. After the approval, we used the triple therapy regimens according to the Japanese government's notice.One to two months after the completion of therapy, including the cessation of acid-secretion inhibitors, the13C-urea breath test and endoscopy were carried out in each patient to determine the $\mathrm{H}$. pylori status. H. pylori infection was considered cured when the bacterial culture, rapid urease test and urea breath test (cut-off value, 3.5 per mil)(19)were all negative. Re-positive test was observed in one patient one year after the eradication therapy, and an additional therapy was performed.

The study was conducted according to the guidelines of the Declaration of Helsinki. A local ethics committee approved the study protocol. The objective of the study was explained to all patients, and written informed consent was obtained from each patient.

Statistical differences were calculated using the Mann-Whitney $U$ test for continuous variables and Fisher's exact test for categorical variables. A $p$ value $<0.05$ was considered to be statistically significant.

\section{RESULTS}

The patients' baseline characteristics are provided in table 1. There was no significant difference between the two groups with respect to age, the percentage of obese patients, or alcohol consumption or detection of gastric cancer during the follow-up period. BMI at 
Table 1 - Patient characteristics

\begin{tabular}{|c|c|c|c|}
\hline & $\begin{array}{c}\text { eradication } \\
\text { group } \\
n=435\end{array}$ & $\begin{array}{c}\text { no-eradication } \\
\text { group } \\
n=167\end{array}$ & $\begin{array}{c}P \\
\text { value }\end{array}$ \\
\hline $\begin{array}{l}\text { Age } \\
\text { (years, mean } \pm S E \text { ) }\end{array}$ & $47.2 \pm 0.3$ & $47.9 \pm 0.5$ & 0.18 \\
\hline $\begin{array}{l}\left(\mathrm{kg} / \mathrm{m}^{2}, \text { mean } \pm \mathrm{SE}\right)\end{array}$ & $22.9 \pm 0.1$ & $23.5 \pm 0.2$ & 0.006 \\
\hline Obesity & $90(20.7 \%)$ & $45(26.9 \%)$ & 0.10 \\
\hline Symptoms* & $105(24.1 \%)$ & $3(1.8 \%)$ & $<0.0001$ \\
\hline Peptic ulcer & $429(98.6 \%)$ & $87(52.1 \%)$ & $<0.0001$ \\
\hline Smoking & $345(79.3 \%)$ & $96(57.5 \%)$ & $<0.0001$ \\
\hline Drinking & $320(73.6 \%)$ & $121(72.5 \%)$ & 0.84 \\
\hline Gastric cancer† & $7(1.6 \%)$ & $4(2.4 \%)$ & 0.36 \\
\hline
\end{tabular}

$\mathrm{SE}$, standard error. *, dyspeptic symptoms or upper gastrointestinal bleeding. †, gastric cancer detected during 10 years follow-up.

baseline in the eradication group $\left(22.9 \pm 0.1 \mathrm{~kg} / \mathrm{m}^{2}\right.$, mean \pm standard error) was significantly lower than in the no-eradication group $\left(23.5 \pm 0.2 \mathrm{~kg} / \mathrm{m}^{2}\right)(\mathrm{p}=0.006)$. Peptic ulcers were more prevalent in the eradication group (98.6\%; gastric ulcer, $n=107$; duodenal ulcer, $\mathrm{n}=181$; gastro-duodenal ulcer, $\mathrm{n}=141$; and no ulcer, $\mathrm{n}=6)$ than in the no-eradication group (52.1\%; $n=34,42$, 11,80 , respectively) $(p<0.0001)$. More smokers were included in the eradication group than in the noeradication group $(p<0.0001)$.

During the 10-year interval, BMI significantly increased from the baseline values in both the eradication group $\left(23.5 \pm 0.1 \mathrm{~kg} / \mathrm{m}^{2}, \mathrm{p}<0.0001\right)$ and in the noeradication group $\left(23.8 \pm 0.2 \mathrm{~kg} / \mathrm{m}^{2}, \mathrm{p}<0.05\right)$ (table 2$)$, but the increase in $\mathrm{BMI}$ was significantly more in the eradication group $\left(0.65 \pm 0.09 \mathrm{~kg} / \mathrm{m}^{2}\right)$ than in the no eradication group $\left(0.25 \pm 0.12 \mathrm{~kg} / \mathrm{m}^{2}\right)$. The difference in the $\mathrm{BMI}$ between the two groups became smaller from $0.67 \mathrm{~kg} / \mathrm{m}^{2}$ at baseline to $0.27 \mathrm{~kg} / \mathrm{m}^{2}$ at 10 years later, when the difference was not statistically significant.

BMI data at one - and five-years follow-up were available in 433 of the 602 patients (the eradication group, $n=314$; the no-eradication group, $n=119$ ). In the no-eradication group, BMI gradually increased throughout the 10-year period almost at a steady rate. The increase from the baseline was not statistically significant at one- and five-year follow-up, but reached statistical significance after 10 years. In contrast, in the eradication group, BMI rapidly and significantly increased from the baseline value at one year $(0.47 \pm$ $\left.0.07 \mathrm{~kg} / \mathrm{m}^{2}\right)(\mathrm{p}<0.0001)$, then gradually increased at about the same rate as that observed in the noeradication group (fig. 1). These findings indicate that
Table 2 - BMI at baseline and after 10 years

\begin{tabular}{lcc}
\hline & $\begin{array}{c}\text { eradication group } \\
\mathbf{n}=\mathbf{4 3 5}\end{array}$ & $\begin{array}{c}\text { no-eradication group } \\
\mathbf{n}=\mathbf{1 6 7}\end{array}$ \\
\hline $\mathrm{BMl}$ at baseline $\left(\mathrm{kg} / \mathrm{m}^{2}\right)$ & $22.9 \pm 0.1$ & $23.5 \pm 0.2$ \\
\hline $\mathrm{BMl}$ at 10 years $\left(\mathrm{kg} / \mathrm{m}^{2}\right)$ & $23.5 \pm 0.1^{*}$ & $23.8 \pm 0.2^{\ddagger}$ \\
\hline
\end{tabular}

mean \pm standard error. ${ }^{*}, \mathrm{P}<0.0001$ vs. baseline; ${ }^{*}, \mathrm{P}<0.05$, vs. baseline

the change in $\mathrm{BMI}$ in the eradication group during the 10-year interval mostly occurred within one year after eradication of $\mathrm{H}$. pylori.

\section{DISCUSSION}

In this study, we investigated the change of $\mathrm{BMI}$ in our Japanese cohort of patients who had been cured of $\mathrm{H}$. pylori infection and had been followed up for 10 years or longer. Control subjects were those who had not received eradication therapy. We found that BMI after 10 years follow-up had significantly increased from the baseline values in both the eradication and the no-eradication groups. However, the BMI increased significantly more in the eradication group than in the no-eradication group. The greater weight gain in the eradication group was due to gain above a lower baseline value, and occurred only during the first year after eradication. The time course of the BMI increase was strikingly different in the two populations: In the eradication group, the BMI increased dramatically during the first year after eradication, but thereafter it increased only gradually. In contrast, BMI in the

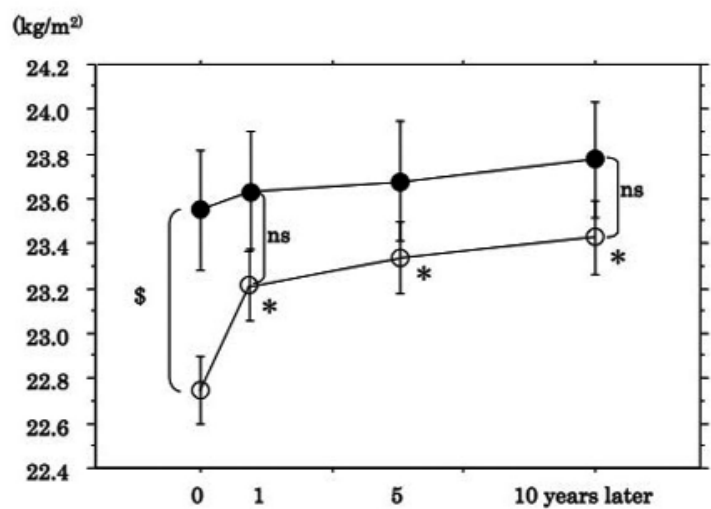

Figure 1 - Body mass index at one, 5 and 10 years follow-up $\circ$, eradication group $(n=314) ; \bullet$, no eradication group $(n=119)$; bars, standard error of the mean. $*, P<0.0001$, vs. baseline. $\$$, $\mathrm{P}<0.05$ eradication vs. no-eradication group. $\mathrm{ns}$, not significant 
no-eradication group increased gradually throughout the 10 years follow-up.

Thus, the influence of $\mathrm{H}$. pylori eradication on BMI seemed to be substantial only during the first year. Others have reported similar findings (11,13-15). Lane JA et al. (16) reported that BMI significantly increased during the first six months after $\mathrm{H}$. pylori eradication, and Kamada et al. (14) found that the early weight-gain effect of eradication had disappeared three years after eradication. Importantly, we found that a similar trend continues for as long as 10 years after $\mathrm{H}$. pylori eradication.

According to the Japanese Ministry of Health, Labor and Welfare (25), the average BMI in males in their 40s was $23.7 \mathrm{~kg} / \mathrm{m}^{2}$, in 1998 , and $23.9 \mathrm{~kg} / \mathrm{m}^{2}$ in their $50 \mathrm{~s}$, in 2008. Compared with these date, the BMI in our noeradication group was comparable to that of the general population, whereas the BMI in the eradication group was lower. The explanation for this observation is not definitely known. However, it may be relevant that the eradication group included significantly more patients with peptic ulcer disease than did the noeradication group. We speculate that the symptoms of peptic ulcer had resulted in reduced dietary intake in the eradication-group subjects, which improved when $\mathrm{H}$. pylori were killed and the ulcers healed. Smoking was more common among the subjects who received eradication therapy, but we doubt that factor alone accounted for their lower BMIs. Detection of gastric cancer during the follow-up period was not different between the two groups. Because more patients with peptic ulcer and smoking habit were included in the eradication group, the preventive effect of $\mathrm{H}$. pylori eradication against gastric cancer could be obscured; but this is not likely to influence the main outcomes of this study.

In addition to the ulcer healing, $\mathrm{H}$. pylori eradication may have influenced hormones, such as ghrelin and leptin, in the gastric wall that regulate appetite and food intake. Ghrelin increases appetite (26), acid secretion (27), gastrointestinal motility (28), and gastric mucosal protection (29). Circulating ghrelin levels were low in $\mathrm{H}$. pylori-infected patients (30) and increased after cure of infection (31). A recent meta-analysis confirmed lower circulating ghrelin levels in $\mathrm{H}$. pylori infected people compared to those not infected, but the effect of eradication of $\mathrm{H}$. pylori on the circulating ghrelin level is controversial (32). Leptin, in contrast to ghrelin, suppresses appetite and enhances energy consumption (33). Leptin mRNA level in the gastric mucosa significantly decreased three months after eradication of H. pylori (34). Taken together, effects of $\mathrm{H}$. pylorieradication on these hormones, the ulcer healing, and other unidentified factors may have contributed the restoration of the lower BMI at one year after the eradication. Thereafter, BMI seemed to increase in both the eradication and the noneradication groups as much as in the general population without $\mathrm{H}$. pylori infection.

In summary, BMl increased after $\mathrm{H}$. pylori eradication, mostly within one year after eradication therapy, but the effect did not seem to last thereafter in our patients-group. BMI increase up to one year after $\mathrm{H}$. pylori eradication may be due to the effect of $\mathrm{H}$. pylori eradication, whereas BMI increase thereafter was not likely to relevant to the eradication; rather it seemed to be the natural change of BMI due to aging, as in the general population. Thus, the long-term change of BMI after $H$. pylori eradication should be regarded as a general health issue and not a deterrent to eradication therapy.

\section{Acknowledgements}

The authors thank to Drs. Tsuyoshi Okamoto, Tomomi Hakoda, Masako Kataoka, Yoshimi Itoh, Rumiko Suzuki, and Hideaki Inoue (Nippon Kokan Fukuyama Hospital) for supporting this work and Dr. William R. Brown (Denver Health Medical Center, Denver, Colorado, USA) for assistance in preparation of the manuscript.

\section{REFERENCES}

1. Rauws EA, Tytgat GN. Cure of duodenal ulcer associated with eradication of Helicobacter pylori. Lancet. 1990 May 26;335(8700):1233-5.

2. Graham DY, Lew GM, Klein PD, Evans DG, Evans DJ Jr, Saeed ZA, et al. Effect of treatment of Helicobacter pylori infection on the long-term recurrence of gastric or duodenal ulcer. A randomized, controlled study. Ann Intern Med. 1992 May 1;116(9):705-8.

3. Hopkins RJ, Girardi LS, Turney EA. Relationship between Helicobacter pylori eradication and reduced duodenal and gastric ulcer recurrence: a review. Gastroenterology. 1996 Apr;110(4):1244-52.

4. Take S, Mizuno M, Ishiki K, Nagahara Y, Yoshida T, Yokota K, et al. The effect of eradicating helicobacter pylori on the development of gastric cancer in patients with peptic ulcer disease. Am J Gastroenterol. 2005 May;100(5):1037-42.

5. Fukase K, Kato M, Kikuchi S, Inoue K, Uemura N, Okamoto S, et al. Effect of eradication of Helicobacter pylori on incidence of metachronous gastric carcinoma after endoscopic resection of early gastric cancer: an open-label, randomised controlled trial. Lancet. 2008 Aug 2;372(9636):392-7.

6. Fuccio L, Zagari RM, Eusebi LH, Laterza L, Cennamo V, Ceroni L, et al. Meta-analysis: can Helicobacter pylori eradication treatment reduce the risk for gastric cancer? Ann Intern Med. 2009 Jul 21;151(2):121-8.

7. Wu CY, Kuo KN, Wu MS, Chen YJ, Wang CB, Lin JT. Early Helicobacter pylori eradication decreases risk of gastric cancer in patients with peptic ulcer disease. Gastroenterology. 2009 Nov;137(5):1641-8.e1-2.

8. Labenz J1, Blum AL, Bayerdörffer E, Meining A, Stolte M, Börsch G. Curing Helicobacter pylori infection in patients with duodenal ulcer 
may provoke reflux esophagitis. Gastroenterology. 1997 May;112(5): 1442-7.

9. Ishiki K, Mizuno M, Take S, Nagahara Y, Yoshida T, Yamamoto K, et al. Helicobacter pylori eradication improves pre-existing reflux esophagitis in patients with duodenal ulcer disease. Clin Gastroenterol Hepatol. 2004 Jun;2(6):474-9.

10. Take S, Mizuno M, Ishiki K, Nagahara Y, Yoshida T, Yokota K, et al. Helicobacter pylori eradication may induce de novo, but transient and mild, reflux esophagitis: Prospective endoscopic evaluation. J Gastroenterol Hepatol. 2009 Jan;24(1):107-13.

11. Azuma T, Suto H, Ito $\mathrm{Y}$, Muramatsu A, Ohtani M, Dojo M, et al. Eradication of Helicobacter pylori infection induces an increase in body mass index. Aliment Pharmacol Ther. 2002 Apr;16 Suppl 2:240-4.

12. Fujiwara $Y$, Higuchi $K$, Arafa UA, Uchida T, Tominaga $K$, Watanabe $T$, et al. Long-term effect of Helicobacter pylori eradication on quality of life, body mass index, and newly developed diseases in Japanese patients with peptic ulcer disease. Hepatogastroenterology. 2002 Sep-Oct; 49(47):1298-302.

13. Furuta T, Shirai N, Xiao F, Takashima M, Hanai H. Effect of Helicobacter pylori infection and its eradication on nutrition. Aliment Pharmacol Ther. 2002 Apr;16(4):799-806.

14. Kamada T, Haruma K, Hata J, Kusunoki H, Sasaki A, Ito M, et al. The long-term effect of Helicobacter pylori eradication therapy on symptoms in dyspeptic patients with fundic atrophic gastritis. Aliment Pharmacol Ther. 2003 Jul 15;18(2):245-52.

15. Kamada T, Hata J, Kusunoki $\mathrm{H}$, Ito $\mathrm{M}$, Tanaka $\mathrm{S}$, Kawamura $\mathrm{Y}$, et al. Eradication of Helicobacter pylori increases the incidence of hyperlipidaemia and obesity in peptic ulcer patients. Dig Liver Dis. 2005 Jan; 37(1):39-43.

16. Lane JA, Murray LJ, Harvey IM, Donovan JL, Nair P, Harvey RF. Randomised clinical trial: Helicobacter pylori eradication is associated with a significantly increased body mass index in a placebo-controlled study. Aliment Pharmacol Ther. 2011 Apr;33(8):922-9.

17. Miyoshi M, Mizuno M, Ishiki K, Nagahara Y, Maga T, Torigoe T, et al. A randomized open trial for comparison of proton pump inhibitors, omeprazole versus rabeprazole, in dual therapy for Helicobacter pylori infection in relation to CYP2C19 genetic polymorphism. J Gastroenterol Hepatol. $2001 \mathrm{Jul} ; 16(7): 723-8$.

18. Adachi M, Mizuno M, Yokota K, Miyoshi M, Nagahara Y, Maga T, et al. Reinfection rate following effective therapy against Helicobacter pylori infection in Japan. J Gastroenterol Hepatol. 2002 Jan;17(1):27-31.

19. Nagahara Y, Mizuno M, Maga T, Ishiki K, Okuno T, Yoshida T, Yokota $\mathrm{K}$, Oguma K, Okada H, Tsuji T. Outcome of patients with inconsistent results from 13C-urea breath test and bacterial culture at the time of assessment of Helicobacter pylori eradication therapy in Japan. Hepatogastroenterology. 2003 Sep-0ct;50(53):1700-3.

20. Take S, Mizuno M, Ishiki K, Nagahara $Y$, Yoshida T, Inaba T, et al. Interleukin-1beta genetic polymorphism influences the effect of cytochrome P 2C19 genotype on the cure rate of 1-week triple therapy for Helicobacter pylori infection. Am J Gastroenterol. 2003 Nov; 98(11): 2403-8.

21. Ishioka H, Mizuno M, Take S, Ishiki K, Nagahara Y, Yoshida T, et al. A better cure rate with $800 \mathrm{mg}$ than with $400 \mathrm{mg}$ clarithromycin regimens in one-week triple therapy for Helicobacter pylori infection in cigarette-smoking peptic ulcer patients. Digestion. 2007;75(2-3):63-8.

22. Take S, Mizuno M, Ishiki K, Nagahara Y, Yoshida T, Yokota K, et al. Baseline gastric mucosal atrophy is a risk factor associated with the development of gastric cancer after Helicobacter pylori eradication therapy in patients with peptic ulcer diseases. J Gastroenterol. 2007 Jan;42 Suppl 17:21-7.

23. Take S, Mizuno M, Ishiki K, Yoshida T, Ohara N, Yokota K, et al. The long-term risk of gastric cancer after the successful eradication of Helicobacter pylori. J Gastroenterol. 2011 Mar;46(3):318-24.

24. Take S, Mizuno M, Ishiki K, Imada T, Okuno T, Yoshida T, et al. Reinfection rate of Helicobacter pylori after eradication treatment: a long-term prospective study in Japan. J Gastroenterol. 2012 Jun; 47(6):641-6.

25. Welfare tJMoHLa. Results from 2008 National Health and Nutrition Survey. 2009

26. Nakazato M, Murakami N, Date Y, Kojima M, Matsuo H, Kangawa K, et al. A role for ghrelin in the central regulation of feeding. Nature. 2001 Jan 11;409(6817):194-8.

27. Masuda $\mathrm{Y}$, Tanaka T, Inomata N, Ohnuma N, Tanaka S, Itoh Z, et al. Ghrelin stimulates gastric acid secretion and motility in rats. Biochem Biophys Res Commun. 2000 0ct 5;276(3):905-8.

28. Asakawa A, Inui A, Kaga T, Yuzuriha H, Nagata $T$, Ueno N, et al. Ghrelin is an appetite-stimulatory signal from stomach with structural resemblance to motilin. Gastroenterology. 2001 Feb; 120(2):337-45.

29. Konturek PC, Brzozowski T, Pajdo R, Nikiforuk A, Kwiecien S, Harsch I, et al. Ghrelin-a new gastroprotective factor in gastric mucosa. J Physiol Pharmacol. 2004 Jun;55(2):325-36.

30. Isomoto H, Ueno H, Saenko VA, Mondal MS, Nishi Y, Kawano N, et al. Impact of Helicobacter pylori infection on gastric and plasma ghrelin dynamics in humans. Am J Gastroenterol. 2005 Aug;100(8): 1711-20.

31. Nwokolo CU, Freshwater DA, O'Hare P, Randeva HS. Plasma ghrelin following cure of Helicobacter pylori. Gut. 2003 May;52(5):637-40.

32. Nweneka CV, Prentice AM. Helicobacter pylori infection and circulating ghrelin levels - a systematic review. BMC Gastroenterol. 2011 Jan 26:11:7.

33. Zhang Y, Proenca R, Maffei M, Barone M, Leopold L, Friedman JM. Positional cloning of the mouse obese gene and its human homologue. Nature. 1994 Dec 1;372(6505):425-32.

34. Azuma T, Suto H, Ito Y, Ohtani M, Dojo M, Kuriyama M, Kato T. Gastric leptin and Helicobacter pylori infection. Gut. 2001 Sep;49(3):324-9. 